\title{
A training model to develop design skills in the virtual design studio
}

\author{
F. Olmos \\ The Bartlett School of Graduate Studies, University College London
}

\begin{abstract}
The design studio is not a common classroom. Its learning model, 'learning by doing', requires practices to be integrated with theoretical knowledge if they are to be internalised by the student. Therefore 'putting into practice' is the keystone for arts and design education in this tradition. Design training consists of a 'reflective practice' with the knowledge, based on physical media such as sketches, drawings and models that will lead design students to develop the skill of 'reflection-in-action'. With the introduction of digital media in the design studio, quantitative and qualitative changes in design training and its practice are to be expected. However, currently there is little understanding of how to incorporate digital and virtual media in the design studio as learning tools, nor of the training value of e-learning technologies in this context. In this paper an experimental introductory design course in a virtual studio is discussed. The results answer some aspects of these two questions. This experience was carried out as a PhD research experiment at the Faculty of Architecture and Arts of the Universidad de Los Andes in Merida, Venezuela. It was aimed to test the feasibility of using e-learning environments for design training in distance learning and presence learning. The e-learning environment, Moodle, was used as a curriculum management system for the theory, as well as for a set of online training programs. The gathering of data to evaluate the course was carried out through two drawing tests, a questionnaire, interviews, student portfolios and direct observation of student performance in the virtual learning environment. The results reveal both the advantages and weaknesses of the e-learning environment tested in the context of a design studio. They also show a consistent development of design abilities in the students who accomplish the vast majority of the training activities in the virtual design studio.
\end{abstract}

Keywords: e-learning, virtual studio, design training, virtual environment. 


\section{Introduction}

Virtual environments and e-learning technologies are becoming very common tools in the architectural field. The possibilities that digital and virtual media are opening in the design process for new conceptions of spatial configurations, is challenging not only the practice but the traditional learning process of design. New approaches to architecture practice based on computer technologies have been developed during the last decades. Since arts and design students are mainly spatial learners there is a high potential for arts and design schools to improve their learning experience with the use of immersive and non immersive Virtual Reality technologies (Byrne [1]). VR technologies have a broad range of applications which go from non immersive experiences based on desktop computers to immersive experiences like the CAVE. Similarly e-learning technologies have evolved into wide range applications and learning strategies.

With the introduction of digital media and virtual environments in the design studio it is expected that the 'reflective practice' will experience a qualitative and quantitative change in the design learning experience. But the introduction of digital and virtual media in the design studio by itself is not a guarantee that it will enhance the learning experience. In fact it could be counterproductive if it is not made with a deep understanding of reflective practice as a learning process and of the limits of information technologies. After more than thirty years of digital drawing in architectural studies there still is not a clear strategy as to how to use computers for 'reflective practices' in the design studio (Szalapaj [7]). Concerns have arisen among tutors of students losing handicraft abilities and therefore design expertise with traditional media and also of the training value of e-learning technologies in this context. The introduction of digital and virtual media in the design studio also challenges some design teaching paradigms, as for instance, the role of the tutor's physical presence or of the material media in the reflective practice.

The design studio learning strategy was defined by Schön [6], as "learning by doing", meaning that the student requires putting into practice the theoretical knowledge in order to learn it. There fore, learning experiences in the design studio should be structured as a training activity in this context. Design training consists of a reflective practice with the knowledge, based on physical media such as sketches, drawings and models that will lead design students to develop the skill of 'reflection-in-action'. Even though the media involved in traditional design studios is material, the reflective practice based on it is primarily a virtual experience. We think with ideas (Hillier [2]), and through the media representation of these ideas we achieve feedback of our design conjectures. Therefore, the possibilities and limitations of any media play an important role in the learning experience.

This experiment was aimed to test the feasibility of using virtual environments and e-learning technologies for arts design training. In order to reach this goal, an experimental virtual studio was created with a non immersive VE using the Open Source software, Moodle, a broadly accepted course management system at a university level. The proposed course syllabus is 
designed to develop a basic theoretical and practical body of knowledge for visual literacy. The experiment introduces and tests a learning model based on the use of design training programs. The evaluation of the effectiveness of the virtual media as a training tool in the design studio accesses the e-learning environment Moodle, and the training model base on the use of design training programs.

\section{A training model for the virtual design studio}

The experimental course in a virtual design studio discussed here is part of a research carried out by Francisco Olmos in his doctoral studies supervised by Alan Penn, at the University College London. The aim of this research is the introduction of e-learning technologies and virtual environments (VEs) in theoretical teaching and practical training in visual arts and design. In this paper, the first experience in a virtual studio at the Architecture and Arts Faculty of the Universidad de Los Andes in Merida, Venezuela, is discussed. This experience was carried out during October and November 2005, with students of the first semester design studio. Eight students participated in this experimental course. The profile of the participating students was quite homogeneous. They were from 17 to 21 years old, and had no previous experience or training in visual arts or design, but they did have a basic experience with computers.

The general picture of a virtual studio created with a set of different available programs, a number of them designed entirely for this course, could be seen as a sort of brick collage. However, this is an experimental course aimed to test the functions, and features of the virtual studio (communication, syllabus, training programs, course management, etc.), independently of the software. The idea was to gather data for developing a virtual learning environment integrating as many functions as possible. The software used for the course could be classified into three groups: Firstly, the operating system and support programs, secondly, the course management system and thirdly, the experimental training programs. The first group, the operating system, Windows XP professional edition and the support programs for the course, Print Screen 32-V3, Cortona VRML Client, DenebaCad and communications tools (Yahoo e-mail group and chat room) are not the object of this study, and therefore, not discussed here. Their particular roles in the course are irrelevant for the purpose of this study. They could be substituted by any other similar programs and what are being studied here are their functions in support of reflective practices in the virtual studio, not the programs themselves.

Moodle [5] was chosen as the course management system due to the learning philosophy that it is based on, social constructivism, and the learning tools and interactivity provided by the program. It is widely used in universities, besides being an Open Source program. These are the main arguments that convinced us to choose Moodle as the course management program, not only for the theory, but also for the practice, based on the design training programs.

The design training programs were written in the VRML programming language. Each provides a virtual training environment for a specific 
bi-dimensional design exercise. There are no drawing programs. They are virtual training tools used to perform design exercises in real time. In Figure 1 the program interface consists of a design area and a set of objects that can be manipulated to some extend, in this case, with lines. The use of controlled objects and functions in basic design training exercises has the purpose of constraining the range of design solutions to the design concepts being studied. This training strategy embedded in the structure of the training programs limits the range of objects and possible configurations. The idea of these constraints is to take the training activities into an abstract level where design ideas are the "raw material out of which all configurational possibility in space and form in the built world are constructed" (Hillier [2]). These constraints focus students on manipulating the configurational concepts more than the forms themselves. On the other hand, the reflective practice depends on feedback received while designing. This feedback also should be controlled by the designer during the reflective practices in order to keep the focus on the design goal. The program helps students control feedback and possible solutions during the training process in a non intrusive way. From the point of view of training the 'mental muscle' these programs are analogous to strength training machines in a gymnasium. They allow students to practice and internalize specific design skills in a controlled situation and can be used in any other design activity.

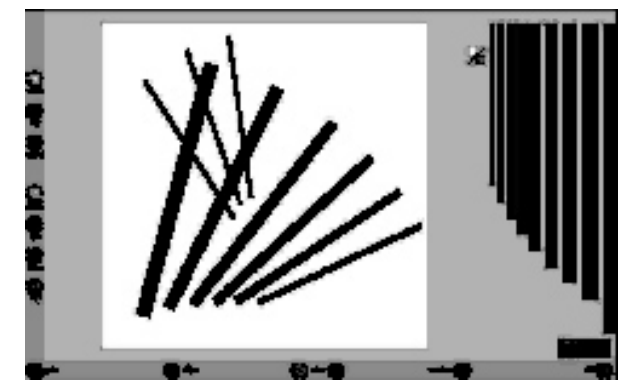

Figure 1.

\section{Assessing the training experience in the virtual studio}

Gathering of data to evaluate the eight week course was performed by means of two drawing tests, a questionnaire, interviews, student portfolios and direct observation of student performances in the virtual learning environment. The methodology for evaluating the experimental course and its components was based on a combination of different research tactics, in which both qualitative and quantitative data were used. The main data gathered was based on two principal sources: Firstly, the study of student performances in design exercises in the virtual learning environments. Secondly, a questionnaire applied to participating students and an interview with them. The categorization and analysis of the data collected from these sources were carried out through triangulation of data and their qualitative and quantitative measures. 
The Moodle e-learning environment proved to be useful as a course management system but there are some concerns about the learning structure for a virtual design studio. Moodle was able to manage students' interactions with the theoretical contents, as well as with the training programs. It was also useful for handing in design exercises and consulting additional information related to the course. However, the learning structure that the program entails is not as flexible as a virtual studio requires. The Moodle learning model organized the course in a sequence of activities grouped by sessions. In this course each session consisted of slide presentations with an introduction to the main features of the design concepts that later will be put into practice. Once the student studies the theory, he/she reads the exercise induction and opens the training program to perform the design exercises. The main concern that arises from the use of this learning environment is the linear structure of activities and the difficulty of integrating both theory and practices. The Moodle learning model does not seem to be the ideal one for self-directed learning or learning on demand strategies which are inherent to reflective practices and require a more flexible structure. On the other hand the questionnaire and the interview reveal that the Moodle interface image is not recognized by the student as one of a virtual design studio. This should be taken into account as a motivational issue. The e-learning environment was able to accomplish all the functions for which it was chosen, but there was a feeling of a lack of a conceptual identity that could affect the presence in the virtual studio and students' motivation.

The training model proposed for the virtual studio based on the use of training programs proves to be an effective learning tool. Most of the design exercises made during the eight week course (13 topics and more than 150 training drawings per students) were carried out with the training programs designed for the course. A Cad program was used in some exercises to free students from the constraints of the training programs to access the internalizations of the design concepts. The comparison between the drawings made with the training programs and the Cad program used in the course confirms the learning value of the training programs. Now we will have a look at the points and lines training program exercises. They consist of applying the design concept of continuity, rhythm, direction, nearness and Kandinsky [3] theory of the picture plane in a composition based on points and lines. Figure 2 shows one of the best compositions made by the students in these exercises and figure 3 , one of the worst. The first case shows a dynamic composition that covers the expectations of the exercise. The second case demonstrates a poor composition with confronting line directions and successions of points. The rhythm is repetitive and static and the composition lacks an illusion of space. Even though the composition doesn't meet exercise expectations the student applied a few design concepts, such as rhythm, nearness and continuity and explored the structure of the picture plane.

The following figures show the same drawing exercises but made with a Cad program. These compositions were made after using the training program. As in the previous cases one is of the best compositions made and the other is of the 
worst. Figure 4 shows a very good application of the design concepts being studied while figure 5 shows a very bad example.

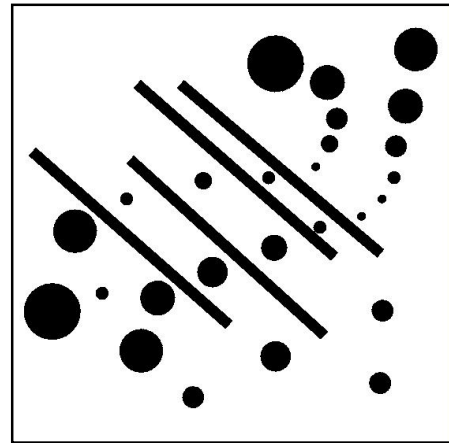

Figure 2.

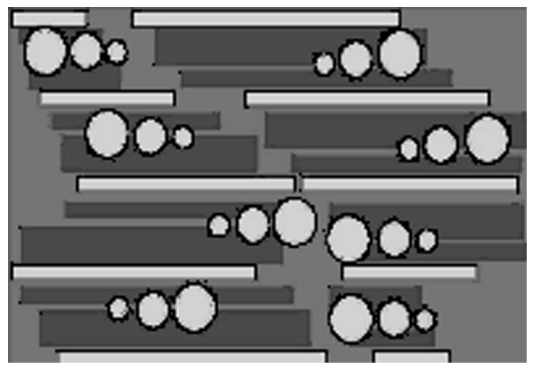

Figure 4.

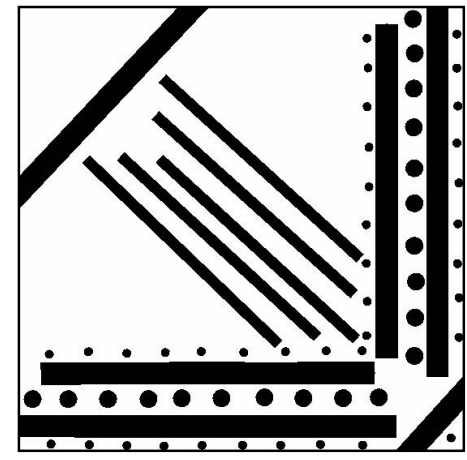

Figure 3.

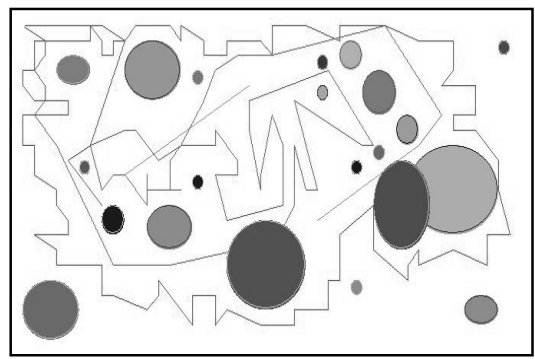

Figure 5.

The remarkable finding here is that the best compositions made with the Cad program are superior to the best compositions made with the training program. However, the poor compositions made with the Cad program are inferior to the ones made with the training program, when it could have been expected that they would have been better as the free students from the constraints of training programs. This tendency also occurred in the other training exercises. This contradiction comes from the controlled parameters of the training programs that help students to keep focused on the training exercise. When a student has not internalized the design concepts yet, the use of a Cad program makes him/her lose the objective of the exercise, which does not happen with the training programs. The number of available virtual tools and drawing possibilities seems to makes students with a lack of training on the use of design concepts get distracted from the exercise objective. On the other hand, students who have internalized the design concepts after accomplishing the training activities, found their own way to use the design concepts when working with a Cad program or any other media, as can be seen also in the final drawing test. 
The knowledge gained through the course was assessed by means of a comparative analysis between the entry drawing test and the final one and the student's training record. At the beginning of the course students were asked to perform a drawing test, which consisted of an abstract composition based on points and lines, using pencils and AA format paper. They were asked to avoid any figurative references. After the eight week introductory virtual studio design course, they were required to do the same drawing test. The comparison between the former and the latter tests, contrasts the design abilities students had at the beginning of the course and the abilities developed throughout the course. The qualitative analysis of both drawings and the student's training record gave a correlation between design training in the virtual studio and the development of design abilities by the students.

This comparison accesses the design ideas used by the students at the beginning of the course and the ones used at the end of it. The evidence that the students had internalized the design concepts through the training process was obvious in their ability to incorporate the concepts in their own designs independently of the media. We will now have a closer look at one of the most representative cases. Figure 6 shows an entry drawing test which lacks spatial representation. It is a flat composition without any focal point or contrast and occupies the whole 'picture plane'. As can be seen, it had an intuitive application of some design concepts, such as continuity and rhythm.

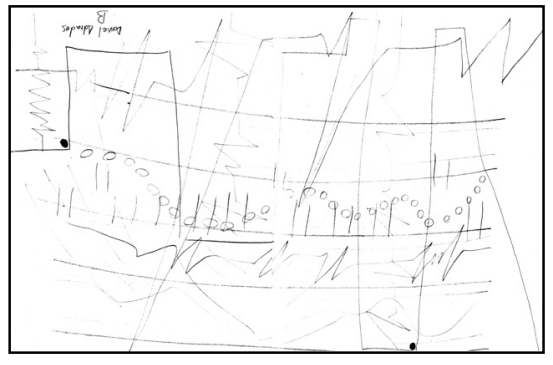

Figure 6.

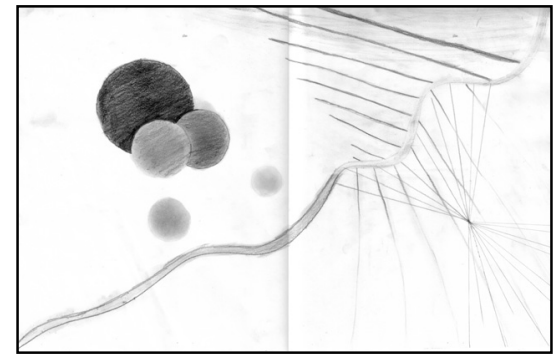

Figure 7.

The final drawing test reveals a dramatic improvement in design abilities at the end of the course. The composition shows the use of design concepts that were internalized by the student during the course. The first remarkable difference is the creation of a spatial composition which doesn't cover the whole format. The composition shows the use of superposition, gradation and tonal contrast to create the illusion of space. There is also an application of other configurational design concepts, such as radiation and the use of contrast in lines, forms and directions. There is also an understanding of the structure of the picture plane as an active element of the composition according to the Kandinsky theory. The curly line which follows the 'harmonious diagonal', reinforced by other lines, creates the illusion of an undulant plane which flows through the 
picture plane. This student accomplished the vast majority of the training exercises and achieved a very good mark at the end of the course.

Figure 8 shows the entry test of a student who's lacking of 'ideas to think with', gets him attached to the figurative representation, even when the instruction to carry out an abstract composition without any figurative references, was emphasized. Even though the composition lacks unity, the right drawing shows the intuitive use of some design concepts, such as module variation and contrast. The final drawing test in figure 9 shows a composition based on a broad set of design concepts. This time the student based the composition in an axial symmetry, reinforced by a rhythmic array of vertical lines at the bottom centre and the horizontal lines on both sides. A virtual curly line crosses these vertical lines. The vertical direction is contrasted with the rhythmic horizontal lines.

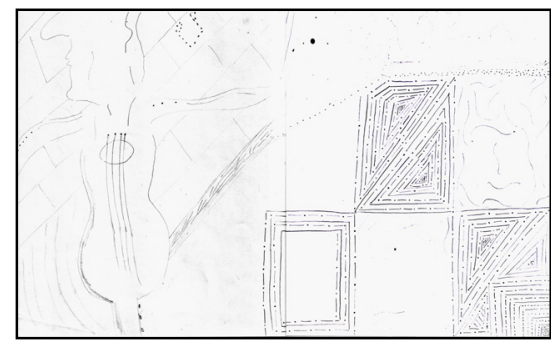

Figure 8 .

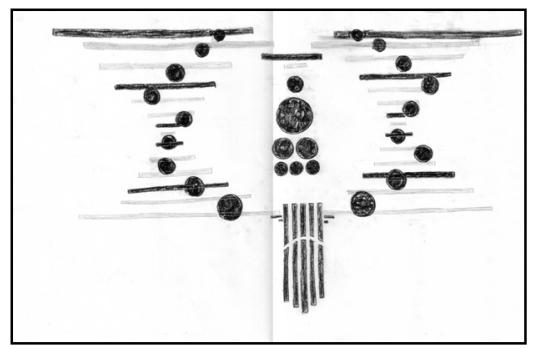

Figure 9.

A subtle illusion of space was created with the horizontal lines using tonal variations. There is a clear conceptual contrast between the use of lines and points. The lines are related to the primary vertical and horizontal directions, but the points follow virtual curved lines around the centre. Lastly, there is a focal point at the centre of the composition created by a group of points. This student accomplished almost all the training exercises and obtained a good mark.

As in most of the cases, the next entry test, Figure 10, evidences the student's lack of 'ideas to think with' (Hillier [2]), at the beginning of the course. Here there is no relevant improvement in the student's design skills. Both compositions had an organic reference even though the design strategies are different. The entry drawing is a composition based on irregular grids of crossing lines, which by filling the spaces between the lines create configurations that share the same family lines.

The final drawing test, Figure 11, shows a different approach to the exercises, even thought it kept the figurative references. The use of some design concepts, such as continuity, module gradation, grouping and contrast, are evident. This student barely accomplished $30 \%$ of the training exercises. Figure 12 shows the direct relationship between the number of training activities accomplished by the students and their final course marks. 


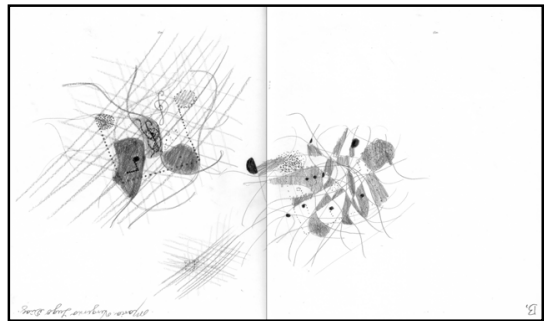

Figure 10.

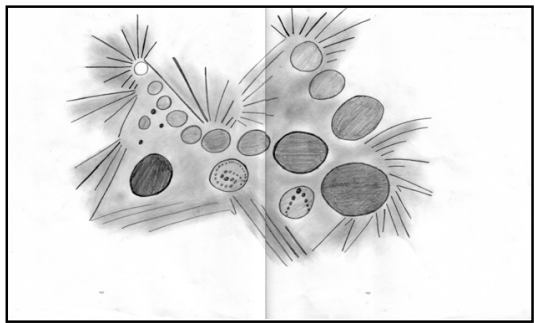

Figure 11.

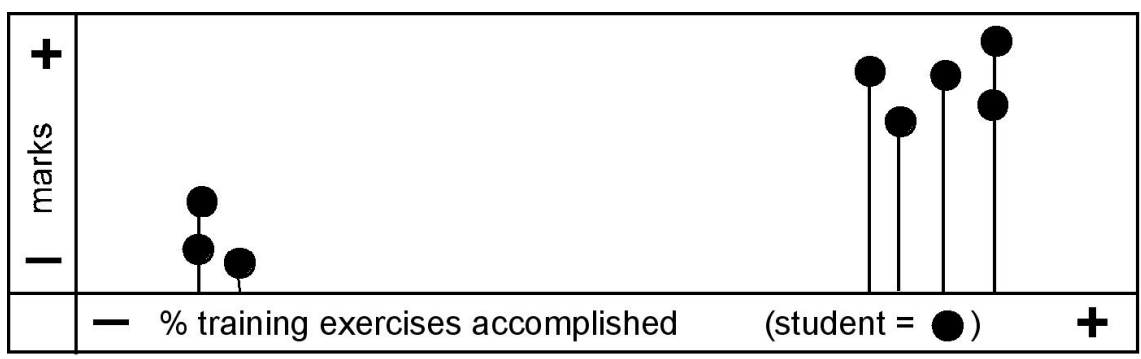

Figure 12.

\section{Conclusion}

The general conclusion of this experimental course is that it works. This was proven by an analysis of the drawing tests. The experiment demonstrated the feasibility of developing design skills in the virtual design studio by digital means, within limits. A limitation comes from the fact that the course only covers basic design concepts from a bi-dimensional point of view. Moreover, the brick collage style of the virtual studio may have caused some type of 'noise or disturbance' in the course of the experiment. However, the training model proposed here, based on the use of the training program, has proven to be an effective training tool in the context of a virtual design studio. The results show that the design concepts were internalized by the students through the use of the training programs. This internalization was in direct contrasting relationship with the number of training exercises accomplished by students. They were able to use these concepts as 'ideas to think with' after the eight weeks course, as evidenced by the final drawing tests. The improvement of design skills in the students proves that the learning strategy of the design studio 'learning by doing' does not depend on the material media, and it is as effective in a virtual studio as in a real one. Even more, the evidence suggests that 'learning by doing' is enhanced in the virtual environment. This is because the 'reflective practice' in design is mainly a virtual experience and the digital media permits performing real time design actions faster than by physical means, such as drawing or modelling. In the same span of time students can have many more meaningful 
and comprehensive virtual design experiences through digital media than by conventional means. Undoubtedly a larger number of design experiences in the same period of time represents a great advantage in design training, because knowledge in design is acquired through the 'reflexive practice' and here the experience makes the difference in the process of knowledge gaining.

The training model proposed here for the virtual design studio has proved to be successful. Even though this is not a conclusive study, there are still some features related to the virtual environment and the training activity to research and improve for the next stage of this $\mathrm{PhD}$ research.

\section{References}

[1] Byrne, Christine M. Water on Tap: The Use of Virtual Reality as an Educational Tool. PhD dissertation. University of Washington 1996.

[2] Hillier, Bill. 1996 Space is the machine: a configurational theory of architecture. New York: Cambridge University Press.

[3] Kandinsky, Vassily: Point and line to plane. Complete writings on art.

[4] Edited by Kenneth C. Lindsay and Peter Vergo; Vol.2, (1922-1943).

[5] Moodle. http://docs.moodle.org/en/Background Accessed: 12/3/2006.

[6] Schön, Donald. 1983. The Reflective Practitioner: how professionals think in action. MIT Press.

[7] Szalapaj, P. 2001 CAD principles for architectural design: an analytical approach to computational representation of architectural form. Oxford: Architectural Press.

[8] Lawson, B. R. How designers think: The design process demystified. Architectural Press. 2000. 